\title{
Erratum to: Seismic risk assessment of building stocks in Indian context
}

\author{
Radhikesh P. Nanda ${ }^{1} \cdot$ Nilendu Krishna Paul ${ }^{1}$. \\ Ningthoujam Monika Chanu ${ }^{1} \cdot$ Sukanti Rout $^{2}$
}

Published online: 7 July 2015

(C) Springer Science+Business Media Dordrecht 2015

\section{Erratum to: Nat Hazards \\ DOI 10.1007/s11069-015-1818-3}

In the initial online publication, the first name of author Ningthoujam Monika Chanu was misspelled as Ninthoujam. The name has been corrected in the publication as shown in this erratum.

The online version of the original article can be found under doi:10.1007/s11069-015-1818-3.

Radhikesh P. Nanda

rpnanda@gmail.com

Nilendu Krishna Paul

nilendukpal@gmail.com

Ningthoujam Monika Chanu

monikachanu2012@gmail.com

Sukanti Rout

sukanti_rout@radiffmail.com

1 Department of Civil Engineering, NIT Durgapur, Durgapur 713209, India

2 Department of Civil Engineering, ITER, SOA University, Bhubaneswar 751030, India 